\title{
Climate Change Trend in Fars Province, Iran and Its Effect on Groundwater Crisis
}

\author{
Nozar Samani, Zahra Jamshidi \\ Department of Earth Sciences, Shiraz University \\ Shiraz, Iran \\ samanin@shirazu.ac.ir; jamshidi.zahra66@gmail.com
}

\begin{abstract}
In recent years, Fars Province in southern Iran has suffered from drought and faced with serious challenges in the water sector, including but not limited to rising water demand and shortage, declining groundwater levels, deteriorating water quality, and increasing ecosystem losses. Climate change is blamed for water crisis. To investigate the trend of climate change and its effect on water crisis, the change-point years in temperature, precipitation and groundwater level time series in Fars Province, Iran were determined for the period 1974-2014 (40 years) and compared with the change year in groundwater level, river discharge and the Southern Oscillation Index (SOI) data. In 12 stations distributed in the province, annual, half-yearly, seasonal and monthly time series were analyzed. The Pettitt-Mann-Whitney, Mann-Whitney-Wilcoxon and Cumulative Sum tests were applied to determine the significance of the detected changes. The result indicates that 1998 and 1995 are the most probable change-point years in the time series of precipitation and temperature, respectively. Compared to the period before 1998 and 1995, annual precipitation and temperature over the province have decreased and increased, respectively. Seasonal precipitation amounts have generally decreased during Autumn, Winter and Spring. In consistence with this finding, the change-point year in SOI time series was found to be the year 1998 that indicates the possible forcing effects of the El Nino-Southern Oscillation (ENSO) phenomenon on the Fars Province climate. Most probably, La Nina phenomenon reduced precipitation in Fars province. However, changes detected in the time series of groundwater level are not consistence with those of climate parameters. It seems that inefficient agriculture sector, mismanagement, over-extraction and thirst for development are main causes for water crisis and the climate change has triggered the crisis.
\end{abstract}

Keywords: Climate change, change-point, Mann-Whitney-Pettitt test, SOI, La Nina

\section{Introduction}

Our planet has experienced climate changes in different geological periods. What makes the present time climate change distinctive is its nature and speed. Of all the climate factors, precipitation fluctuations generally have the greatest impact on the economies of rich and poor countries. To detect and identify climate change, many research conducted on the trends of precipitation in recent decades. Morrissey and Graham [1] and Chen et al. [2] introduced the mid-1970s as the change year in global temperature and precipitation time series data. Kiely [3] review climate change in Ireland using precipitation and river discharge data and has concluded that the increase in precipitation and river discharge in Ireland was associated with fluctuations in air pressure in the North Atlantic. Filion [4] investigated climate change and its effect on Canadian water resources and hydroelectric power generation. He concluded that increase in temperatures will increase water consumption in summer which in turn reduces hydroelectric power generation. Nazemosadat et al. [5] examined the effect of the El Nino-Southern Oscillation (ENSO) phenomenon on climate change in Iran. The results indicated a change in the mid-70s in the Southern Oscillation Index (SOI) and time series of precipitation in Iran. Du et al. [6] studied dry and wet conditions by using standardized precipitation index (SPI) to identify the notable change point in precipitation time series.

In this paper the annual, first half-yearly (October to March) and second half-yearly (April to September), seasonal and monthly time series of precipitation and temperature (in 33 stations), SOI and river discharge as well as the annual and October time series of groundwater level are analysed. Then the most probable change-point in each time series was calculated. Finally, changes in the SOI as an effective factor on climate change in Fars province and percent decrease in precipitation after the change year in the studied stations were evaluated. The main cause of groundwater crisis with respect to climate change is also defined. 


\section{Materials and Methods}

Long-term precipitation data from 33 rain gauge stations, discharge data from two hydrometric stations and temperature data from four Meteorology stations and water level data of 16 plains for the period of 1974-2014 in Fars province were collected. Position of these stations is presented in Fig. 1. SOI data for period 1974-2014 was prepared from Australian Bureau of Meteorology. According to the Iran's water year, annual (from October to September of the following year), first half-yearly (October to March), second half-yearly (April-September), Autumn (October-December), Winter (January to march), Spring (April to June) and Summer (July to September) time series were extracted. PettittMann-Whitney and Cumulative sum tests that explained by Pettitt [7] were used to estimate change point in time series. Then Mann-Whitney-Wilcoxon test were used for identifying the statistical significance of change points [7].

In Pettitt-Mann-Whitney test, every time series with length $\mathrm{T}$, given by $\left(X_{1}, \ldots, X_{T}\right)$ is considered as two samples represented in the form of two series $\left(X_{1}, \ldots, X_{t}\right)$ and $\left(X_{t+1}, \ldots, X_{T}\right)$ and the Indice $\mathrm{U}(\mathrm{t})$ and $\mathrm{V}(\mathrm{t})$ are calculated as follows:

$$
V_{t, T}=\sum_{j=1}^{T} \operatorname{sgn}\left(X_{t}-X_{j}\right)
$$

Where

$$
\begin{aligned}
\operatorname{sgn}(\mathrm{x})=1 \quad \text { for } \mathrm{x}>0 \\
\operatorname{sgn}(\mathrm{x})=0 \quad \text { for } \mathrm{x}=0 \\
\operatorname{sgn}(\mathrm{x})=-1 \quad \text { for } \mathrm{x}<0 \\
U_{t, T}=U_{t-1, T}+V_{t, T} \quad \text { for } \mathrm{t}=2, \mathrm{~T}
\end{aligned}
$$

Where

$$
U_{1, T}=V_{1, T}
$$

The approximate significance probability $\mathrm{p}(\mathrm{t})$ for a change-point is

$$
p(t)=1-\exp \left[\frac{-6 U_{t, T}^{2}}{T^{3}+T^{2}}\right]
$$

The most notable change-point is found where the value $\left|U_{t, T}\right|$ or $p(t)$ is a maximum. In addition to the $p(t)$ test, the Cumulative sum was also used to identify the change point in the time series. Cumulative sum (cum sum) is calculated as follows:

$$
S_{j}=\sum_{i=1}^{j}\left(X_{j}-\bar{X}\right)
$$

$\bar{X}$ is the mean value of time series. The possible change occurs when $S_{\mathrm{j}}$ is a maximum. We selected the change point where both $S_{\mathrm{j}}$ and $\mathrm{p}(\mathrm{t})$ were maximum. 


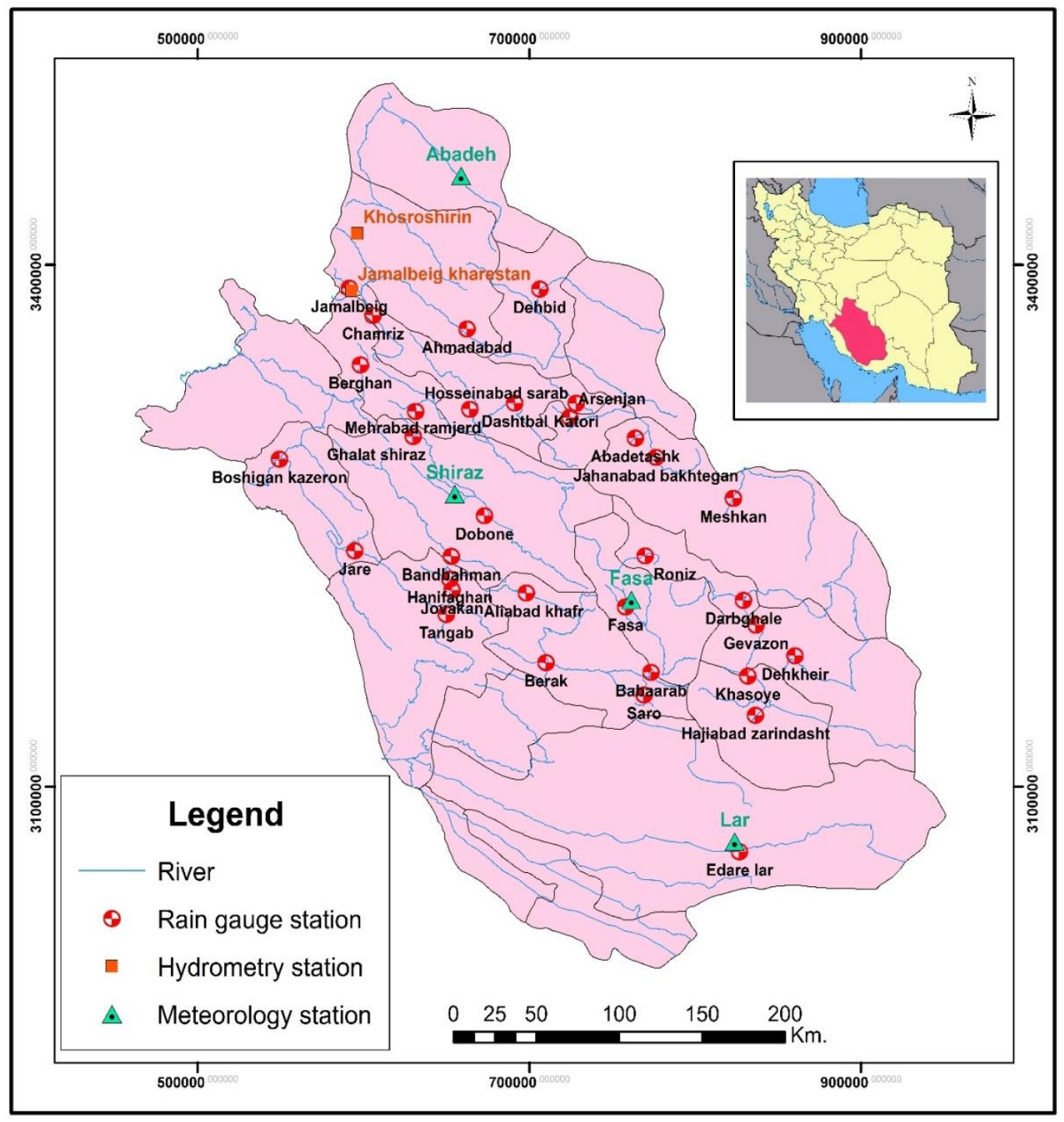

Fig. 1: Position of Hydrometry, Meteorology and Rain gauge stations in Fars Province.

\section{Results and Discussion}

The initial assessment of variation in the scaled precipitation, temperature, discharge and SOI time series was made by plotting long term mean line, linear trend line and 5-year moving average curve of annual time series. As an example, Fig. 2 shows the decreasing trend of precipitation in Babaarab and Band bahman stations. The decreasing trend falls below the mean line in the second mid of 1990 which may be the rough estimation of the most probable change point. Then, using the statistical methods described above the change point in each of time series was calculated by plotting the $p(t)$ and cum sum functions. 

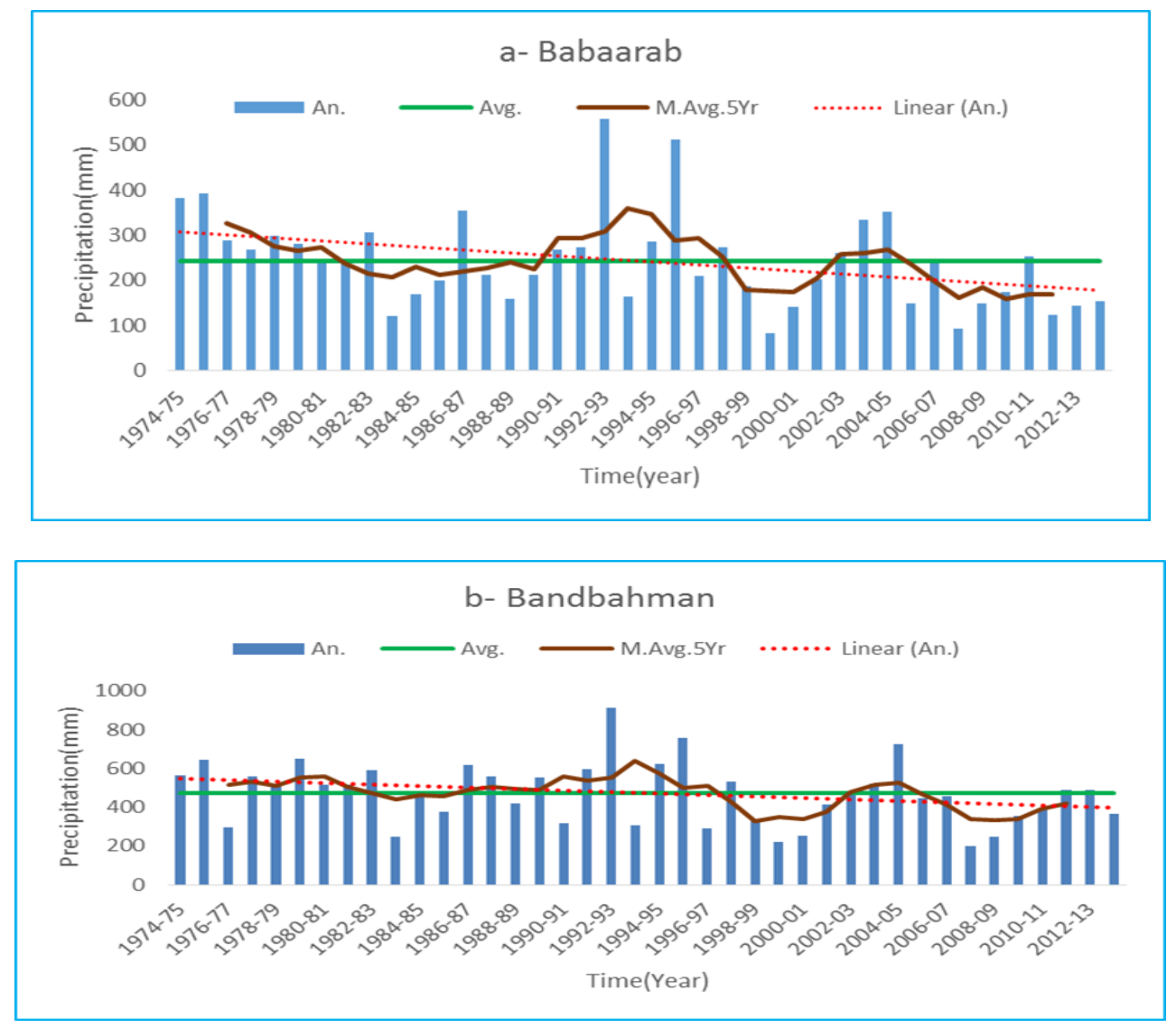

Fig. 2: Annual precipitation (An.), mean, Linear trend and 5-year moving average in Babaarab (a) \& Band bahman (b) stations for period 1974-2014.

For the sake of brevity, only Fig. 3 was illustrated for the annual and March time series in Babaarab and Band bahman stations. The maximum value of the two functions that overlap shows the change point. Change point and the significant probability for the annual and March time series in Babaarab and Band bahman stations are [1997-98, 0.981], [1998, 0.992], [1995-96, 0.976] and [1998, 0.996], respectively. Change points with significant probability in precipitation time series for all stations are generally in the second half of 1990s. In most of the studied stations, 1998 was identified as the most probable change-year point in precipitation time series.

\subsection{Precipitation before and after Change-Year}

To determine the percentage reduction after the change-year the mean annual hyetograph for the period of (1974-1914, full record), (1974-1998, before the change-year) and (1999-2914, after the change-year) are calculated and presented in Fig. 4. Figure 4 is self-explanatory. The greatest reduction in precipitation is in February and March in Winter and October in the Autumn season. Reduction in precipitation in October, February and March is $17 \%, 36 \%$ and $65 \%$, respectively. In all other stations, there are reduced precipitation after the change year in annual, first half-yearly (October to March), second half-yearly (April to September), Winter, Autumn and Spring precipitation time series (Table 1), negative sign indicates decrease. 

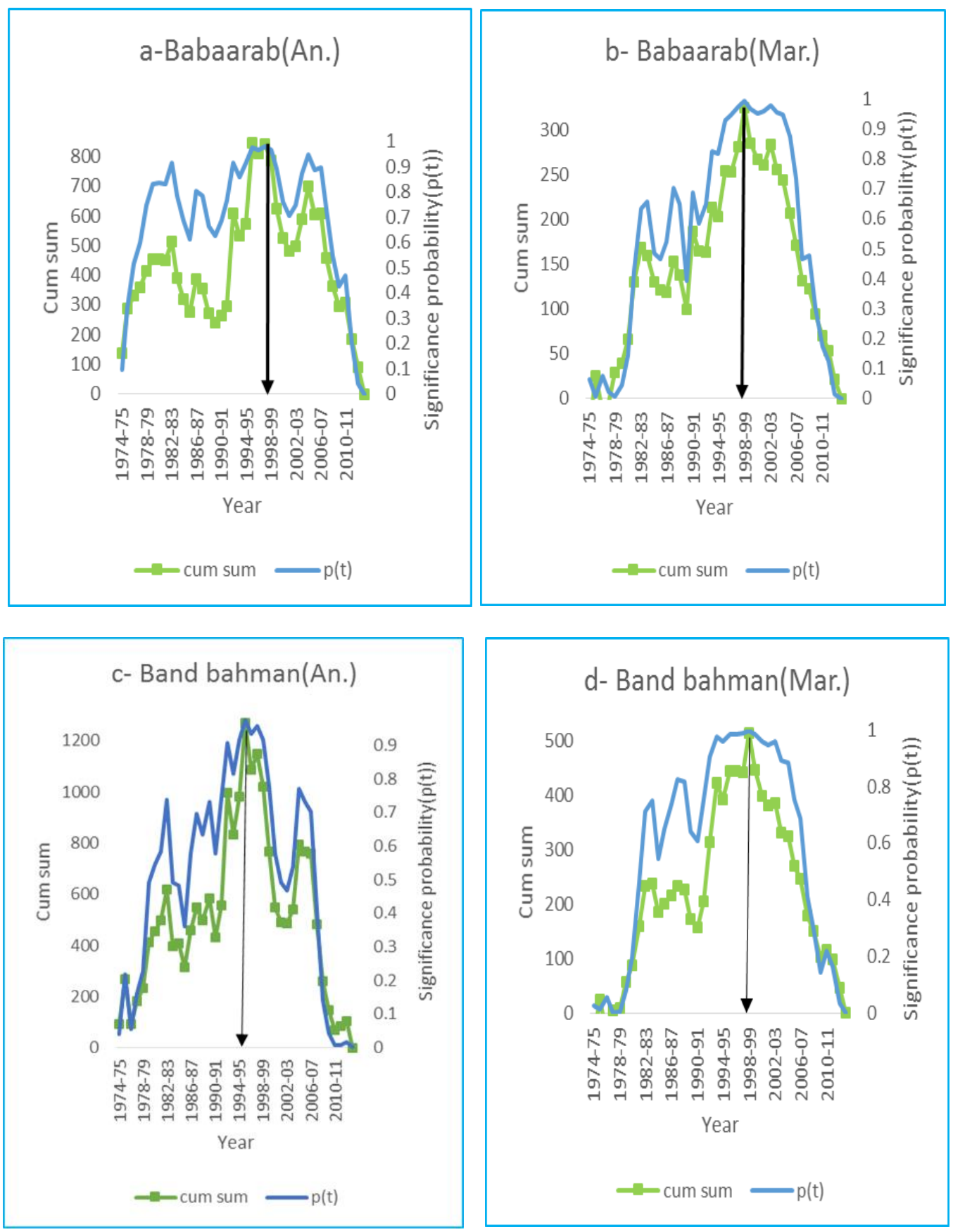

Fig. 3: Significance probability and cumulative sum of time series for Annual and March precipitation in Babaarab and Band bahman (1974-2014). 

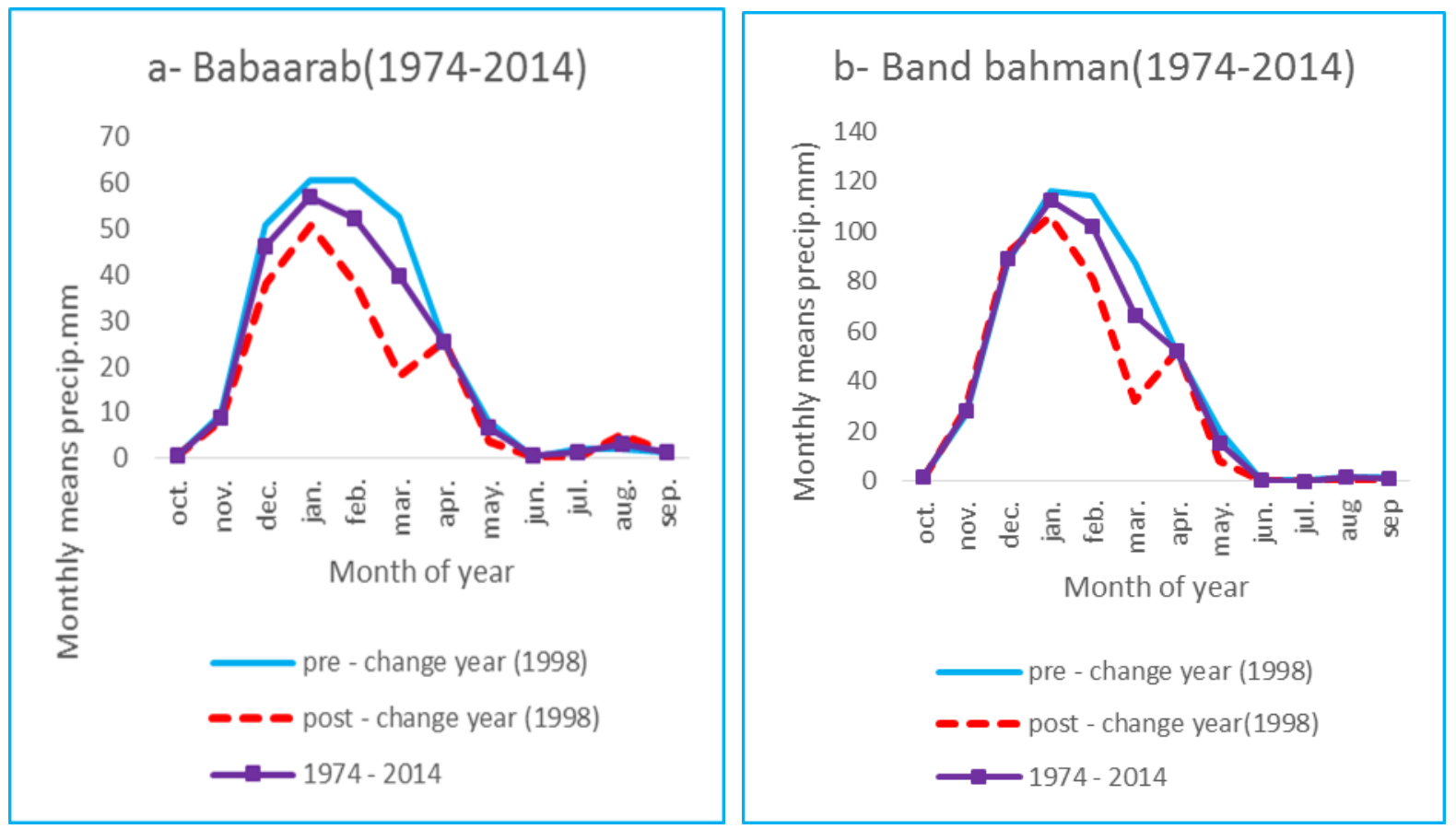

Fig. 4: Mean hyetograph for 1974-2014, pre-and post-change year (1998) in Babaarab (a) and Band bahman (b) station.

Table 1: Percentage changes in precipitation: annual (An.), first half-yearly (6m1) and second half-yearly (6m2), autumn(A), winter (W), and spring (Sp) after the change year (1998) in 12 precipitation stations.

\begin{tabular}{|l|c|c|c|c|c|c|}
\hline Station name & $\mathbf{A n}$. & $\mathbf{6 m 1}$ & $\mathbf{6 m 2}$ & $\mathbf{A}$ & $\mathbf{W}$ & $\mathbf{S p}$ \\
\hline Ahmadabad & $*-31.04 \%$ & $-33.42 \%$ & $-19.07 \%$ & $-34.43 \%$ & $-32.93 \%$ & $-17.34 \%$ \\
\hline Arsenjan & $-19.73 \%$ & $-20.15 \%$ & $-17.78 \%$ & $+3.85 \%$ & $-28.54 \%$ & $-15.45 \%$ \\
\hline Babaarab & $-30.53 \%$ & $-34.52 \%$ & $-7.02 \%$ & $-22.98 \%$ & $-38.56 \%$ & $-12.05 \%$ \\
\hline Band bahman & $-21.23 \%$ & $-21.37 \%$ & $-20.43 \%$ & $+4.31 \%$ & $-30.87 \%$ & $-16.85 \%$ \\
\hline Brghan & $-15.11 \%$ & $-13.74 \%$ & $-21.98 \%$ & $-3.58 \%$ & $-17.95 \%$ & $-21.16 \%$ \\
\hline Boshigan & $-20.31 \%$ & $-18.67 \%$ & $-31.76 \%$ & $-2.36 \%$ & $-26.30 \%$ & $-33.27 \%$ \\
\hline Dobone & $-15.44 \%$ & $-17.49 \%$ & $-3.33 \%$ & $+10.41 \%$ & $-27.57 \%$ & $-4.68 \%$ \\
\hline Ghalat shiraz & $-11.86 \%$ & $-12.57 \%$ & $-8.14 \%$ & $-1.31 \%$ & $-17.45 \%$ & $-10.50 \%$ \\
\hline Jamalbeig & $-12.38 \%$ & $-13.99 \%$ & $-4.44 \%$ & $-0.18 \%$ & $-20.46 \%$ & $-3.22 \%$ \\
\hline Jare & $-17.79 \%$ & $-17.90 \%$ & $-17.04 \%$ & $+0.70 \%$ & $-26.37 \%$ & $-18.85 \%$ \\
\hline Jovakan & $-17.76 \%$ & $-20.08 \%$ & $-3.82 \%$ & $+8.01 \%$ & $-30.86 \%$ & $-1.35 \%$ \\
\hline Edare lar & $-44.37 \%$ & $-46.11 \%$ & $-38.31 \%$ & $-11.16 \%$ & $-56.32 \%$ & $-31.60 \%$ \\
\hline
\end{tabular}

\subsection{Change Year in the SOI Time-Series}

The Troup [8] SOI data extracted from the web site of the Australian Bureau of Meteorology (www.bom.gov.au) was used as the ENSO indicator. If the change-point years in precipitation and SOI data were mostly coincident and the signs of the trend for the period before and after these years was consistent in both time series, ENSO could be considered as the external mechanism for climate change in Fars Province. Annual SOI time series for 40-year period 
together with the linear trend line and 5-year moving average were plotted (not shown) for the initial estimate of changeyear. An increasing trend in the SOI in the second mid of 90s were observed. To determine the most probable change-year point in SOI time series, Mann Whitney Pettit and Cumulative sum tests were used (the same as precipitation time series). As indicated in Table 2, like precipitation time series, 1998 is the most probable change-point years in the SOI time series stratified into annual, half-yearly, quarterly and monthly timescales.

Table 2: Change year \& Significance probability for annual, seasonal, monthly and half-yearly SOI time series (1974-2014).

\begin{tabular}{|c|c|c|c|c|c|c|}
\hline SOI time series & An. & $6 \mathrm{~m} 1$ & $\mathbf{A}$ & Mar. & Nov. & Apr. \\
\hline Change year & $1997-98$ & 1998-99 & 1997 & 1998 & 1997 & 1998 \\
\hline $\begin{array}{l}\text { Significance } \\
\text { probability }(p(t))\end{array}$ & 0 . & 0 & & 37 & 0.904 & 0.953 \\
\hline
\end{tabular}

Average monthly SOI before and after change year (1998) is shown in Figure 6. As it can be seen, the average SOI after change year is positive in all months except in the Summer months (May, June and August). In contrast, before the change year it is negative in all months. This implicates that the La Nina phenomenon after change year causes a decrease precipitation in winter and spring in Fars Province.

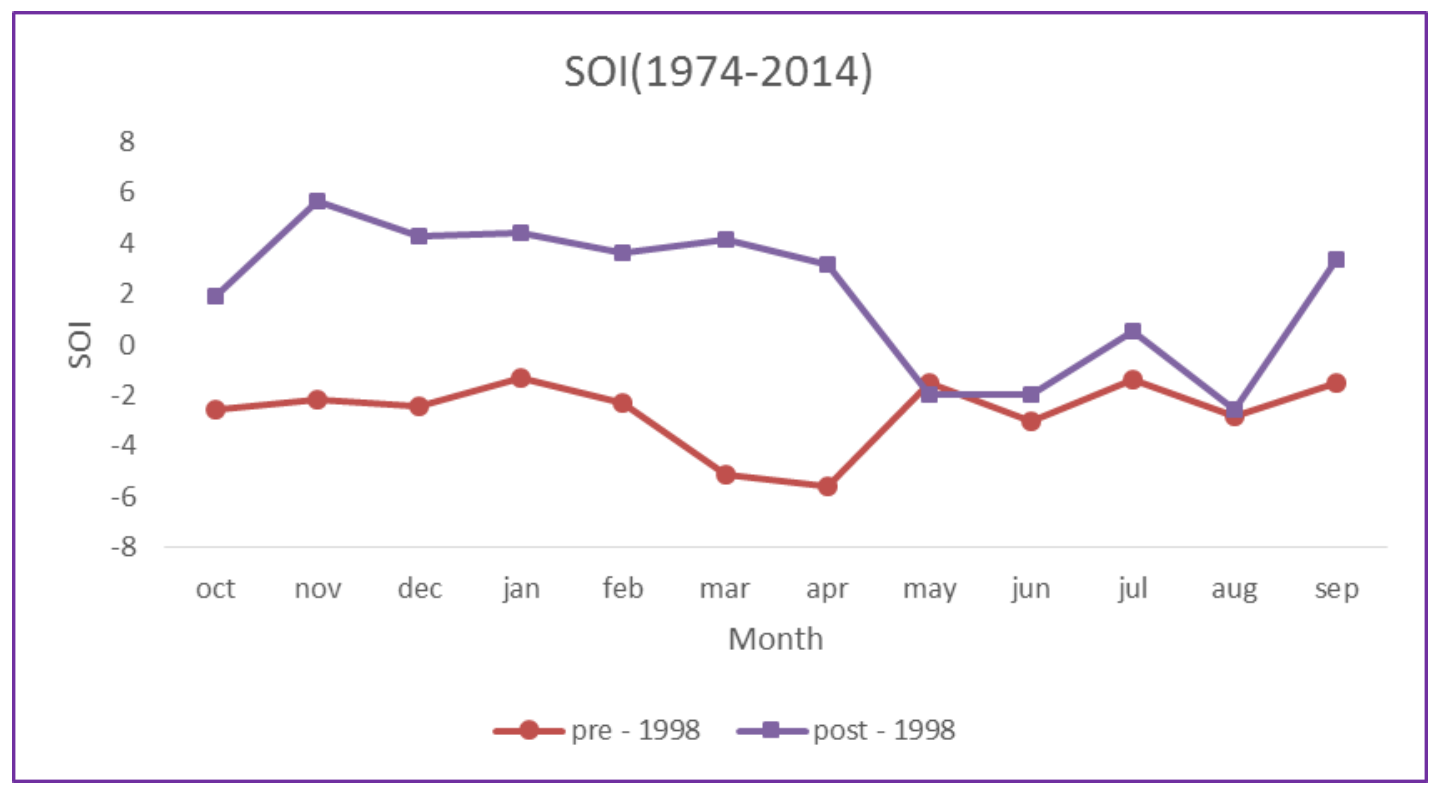

Fig. 6: Average monthly SOI before and after the change-year (1998).

\subsection{Change Years in the Temperature, River Discharge and Groundwater Level Time-Series}

The change-year points in the scaled time series of temperature (in 3 stations), river discharge (in 2 stations) and groundwater level (in 16 aquifers) were also estimated by the above-mentioned procedures. It was found that the changeyear in the temperature time series happened in mid 90s a few years before the change-year in precipitation. River discharge data showed 1998 as the change year too. However, the change-year in the groundwater lever varied from 2000 to 2008 in different aquifers. It seems that the groundwater level started to decline just after 1998 (the precipitation changeyear) and triggered due to inefficient agriculture sector, mismanagement, over-extraction and thirst for development in the following years creating the water crisis in the province.

\section{Conclusion}

The study has demonstrated that for the scaled precipitation, temperature, river discharge and SOI time series the change-year points occur in the second mid of 1990s. The scaled precipitation and temperature time series reduced and increased after the change-year point, respectively throughout the Fars Province. The average monthly SOI before and after 
the change year represents an increase in SOI after 1998. A clear synchronization between hydrological and climate data are observed. La Niña phenomenon is likely to reduce precipitation in Fars province in Autumn and Winter seasons. Changes detected in the time series of groundwater level are not sharply consistence with those of climate parameters. It seems that inefficient agriculture sector, mismanagement, over-extraction and thirst for development are main causes for water crisis and the climate change has triggered the crisis.

\section{Acknowledgements}

We thank the Water and Climatology Bureau of Fars Province, Iran for providing us with data.

\section{References}

[1] M. L. Graham Morrissey, "Recent trends in rain guage precipitation measurements from the Tropical Pacific," Bull.Am.Meteor.Society, vol. 77, pp. 207-19, 1996.

[2] T. S. Chen, J. M. Chen, C. K. Wikle, "International variation in US Pacific coast precipitation over the past four decades," Bull.Am.Meteor.Society, vol. 77, pp. 197-205, 1997.

[3] G. Kiely, "Climate change in Ireland from precipitation and streamflow observations," Advances in W.R, vol. 23, pp. 141-151, 1999.

[4] M. H. Filion, "Climate change: Implications for Canadian Water Resources and Hydropower Production," Canadian W.R.J, vol. 25, pp. 255-269, 2000.

[5] M. J. Nazemosadat, N. Samani, D. A. Barry, M. Molaii Niko, "ENSO forcing on climate change in Iran, Precipitation analysis," Iranian Journal of Science and Technology, Transaction B, Engineering, vol. 30, pp. 55565, 2006.

[6] J. Du, J. Fang, W. Xu, P. Shi, "Analysis of dry/wet conditions using the standardized precipitation index and its potential usefulness for drought/flood monitoring in Hunan Province," China. Stoch Environ Res Risk Assess, vol. 27, pp. 377-387, 2013.

[7] A. N. Pettitt, "A nonparametric approach to the change point problem," App. Statist, vol. 28, pp. 126-35, 1979.

[8] A. J. Troup, “The Southern Ocillation,” Q.J.R. Meteorol. Soc., vol. 91, pp. 490-506, 1965. 